\title{
Cooperação e autonomia: desafios das cooperativas populares
}

\author{
Jacyara C. Rochael Nasciutti, Fabiana Silveira Dutra, \\ Juliana Santana Matta e Tatiana Ramos de Lima ${ }^{1}$
}

\begin{abstract}
Alternativa possível à exclusão do mercado formal de trabalho, o trabalho cooperativado nas classes trabalhadoras esbarra nas hierarquias sociais (relações de dominação), mas insiste na disposição cidadã e na solidariedade emergente através de uma cultura que se instala. A legitimação de um novo lugar psicossocial se faz presente no discurso de cooperativados, conforme dados desta pesquisa, em uma abordagem institucional, realizada em cooperativas populares urbanas na cidade do Rio de Janeiro. Os resultados, a partir de entrevistas e observação participante, apontam para a percepção da eficácia da ação coletiva, dos frutos da solidariedade e da cooperação na geração de renda e da possibilidade de outras formas de vínculos de trabalho que não passem necessariamente por relações instituídas de sujeição. A mudança na auto-estima, a consciência de potencialidades desconhecidas, re-situam o trabalhador frente a seu grupo social. Por outro lado, a carteira assinada, título de cidadania em nossa organização social, acena como um elemento que, por sua ausência do universo cooperativado, interfere, além dos entraves burocráticos estatais, no investimento que os trabalhadores fazem na instituição cooperativa.
\end{abstract}

Palavras-chave: cooperativismo popular, comunidade, sujeito social.

\section{Cooperativas populares: a autogestão em questão}

E mbora a instituição cooperativa exista há mais de um século no mundo, há mais de cinqüenta anos no Brasil e embora seus princípios fundadores sejam abarcados em regimes políticos os mais distintos, suas propostas de cunho coletivista e solidário são estranhas ao modo de produção capitalista, que produz não só bens, mas subjetividades.

Formas associativas e solidárias de atuação comunitária constituem modo privilegiado de participação dos atores sociais na gestão das questões comuns à comunidade. A esse propósito, assinala-nos Pajoni (1996): "Nenhuma ação ou projeto urbano pode ocorrer isoladamente, sem a participação de diferentes atores. É a atividade dos habitantes que produz o urbano, que não pode ter sua gestão centralizada apenas nos poderes públicos" (p. 184).

As ações coletivas fortalecem o sentimento de "pertença" e solidificam os vínculos comunitários, permitindo a elaboração e o engajamento conjunto em projetos locais. Projetos de ação comunitária podem se revelar como riquíssimos elementos de construção de cidadania, de resgate da auto-estima, de conscientização, em última análise, do lugar que cada ator ocupa no mundo social. Ao vislumbrar a possibilidade da solidariedade e da ação conjunta em benefício comum, o novo cidadão estará também mais atento ao que lhe cerca.

Nosso intuito com essa pesquisa foi o de apreender os modos de existência no espaço social-econômico desse tipo de instituição, em sua forma popular e urbana na realidade atual

\footnotetext{
${ }^{1}$ Programa Eicos do Instituto de Psicologia da Universidade Federal do Rio de Janeiro.
} 
brasileira. Isso significou, em nossos propósitos, analisar o processo de criação, institucionalização e atuação de cooperativas populares urbanas, alcançando os diferentes atores sociais envolvidos nessa forma de instituição.

Buscamos verificar de que formas os princípios da doutrina do cooperativismo estão sendo aplicados e respeitados na formação e gestão de cooperativas populares urbanas e como esses princípios são representados no discurso dos cooperativados e dos técnicos e em suas práticas cotidianas. Esses aspectos merecem ser investigados, uma vez que a lógica do cooperativismo, que marca um paradigma diverso de relações de trabalho, parece, às vezes, sucumbir à força das representações no imaginário social que preside a distribuição de lugares no mercado de trabalho e reproduzem em suas práticas modelos tradicionais das relações de poder no mundo do trabalho.

Como objetivo último, nossa proposta foi a de analisar de que forma as cooperativas populares, enquanto agentes da democracia econômica/social (em que conceitos como participação, cooperação, "empoderamento" e consciência social fazem parte do vocabulário ideológico proposto), conseguem efetivar, em suas práticas, o discurso de facilitação da criação de um cidadão consciente de seu lugar histórico-social, senhor de sua força de trabalho. E, ainda, verificar a forma real de atuação dessas cooperativas em termos de relações alternativas de trabalho e inserção social frente ao modelo econômico vigente. Entendemos que nosso olhar de pesquisadores preocupados com a função social da universidade brasileira pode contribuir, através da reflexão sobre as práticas, para a reelaboração de modelos produtivos que sejam também produtores do bem-estar psicossocial da população brasileira.

O crescimento vertiginoso no número de cooperativas no Brasil, nos últimos dez anos $^{2}$ parece apontar esse tipo de organização como alternativa viável ao desemprego crescente e às mudanças no sistema de produção econômica. No entanto, embora as ciências humanas e sociais tenham se dedicado à análise de questões referentes à sua eficiência, às vantagens e desvantagens no mercado de trabalho e na estrutura produtiva e à garantia de sobrevivência econômica da própria cooperativa e de seus cooperados, poucos estudos têm sido realizados no sentido de se pensar a ressignificação do lugar do sujeito social através da estrutura cooperativista, que aponta para relações sociais, institucionais e de trabalho diferentes daquelas cristalizadas no modelo empresarial tradicional e para o redimensionamento do sentido subjetivo do trabalho.

A literatura pesquisada, as entrevistas preliminares realizadas com técnicos de incubadoras de cooperativas populares no Rio de Janeiro (FASE, SEBRAE e Incubadora Tecnológica de Cooperativas da Coppe/UFRJ) e as conversas informais com lideranças comunitárias e membros de cooperativas conduziram à elaboração de várias questões que norteiam, em princípio, esse trabalho.

Mesmo sem a pretensão de encontrar respostas conclusivas para todas elas, buscamos nos aproximar do cotidiano dessas instituições, de suas práticas, das relações mantidas entre congêneres e com o ambiente no qual existem; procuramos ouvir seus integrantes, seus propósitos, motivações, avaliações, queixas e aspirações. Aproximando-nos desse universo, nossos olhares se dirigiram para a apreensão de aspectos relacionados às seguintes questões: As cooperativas conseguem existir como uma "terceira via" numa estrutura socioeconômica viciada pelo clientelismo e pelo poder do capital? Como acontece a dinâmica institucional de uma cooperativa popular? Estariam as cooperativas populares reproduzindo estruturas de poder centralizadas e verticais vigentes nas organizações de trabalho de onde são oriundos seus integrantes? O modelo cooperativista promove o "empoderamento" do trabalhador, tirando-o da exclusão social e devolvendo-lhe o lugar de ator social? $\mathrm{O}$ cooperativado

\footnotetext{
${ }^{2}$ Registra-se crescimento de 300\% neste período, num total de 4 milhões de cooperativados (cf. Martins, 1999).
} 
conhece a doutrina cooperativista e reconhece-a em sua cooperativa? Que mudanças ocorrem na sua relação com o outro, com a família, com o próprio trabalho, na sua autoestima, nas suas perspectivas de vida, quando passa de empregado a cooperativado? O que esse indivíduo busca na cooperativa? Qual o lugar das mulheres nas cooperativas populares?

As abordagens históricas, conceituais e teóricas do universo cooperativista que precederam o trabalho de campo podem ser conferidas em um artigo publicado na revista Documenta EICOS (Nasciutti, 2000) e em outros vários trabalhos ali referenciados. Retomaremos aqui brevemente, algumas considerações essenciais para melhor compreensão de nossos dados.

Roberto Rodrigues, atual Ministro da Agricultura, enquanto presidente da Aliança Cooperativa Internacional, definiu o cooperativismo, em entrevista concedida ao Jornal do Brasil, como "doutrina universal, aceita em todos os regimes econômicos, sociais e políticos (...) que visa corrigir o social investindo no econômico" (Rodrigues, 1999a). No entanto, ele aponta para mudanças no perfil atual das cooperativas que implicariam numa redefinição do próprio conceito, que passaria a incluir o lucro, a competitividade, a integração de um perfil técnico-empresarial das lideranças como elementos contraditórios, mas (segundo ele) inevitáveis, gerados pela globalização. Ele afirma ainda (1999b) que a globalização e a falência do modelo socialista provocaram uma reviravolta no cooperativismo mundial, destruindo seus limites e criando uma verdadeira crise de identidade do cooperativismo. A tendência apontada por esse autor é de que as cooperativas se adaptem às novas diretrizes do mercado para sobreviver, devendo se tornar competitivas, ágeis e lucrativas. Essa visão, que parece se tornar predominante cada vez mais na defesa da inserção competitiva das cooperativas no mercado brasileiro, adaptando-as ao modelo capitalista e globalizado, nega a própria doutrina universal do cooperativismo - definida pelo próprio Roberto Rodrigues - e atua na contramão da proposta autogestora e democrática do cooperativismo.

Assim, de uma proposta inicial de se constituir numa "terceira via", as cooperativas passam a se inserir nos parâmetros do mercado de forma competitiva, isto é, empresarial e centralizadora. As mudanças mais evidentes parecem ser a não-participação dos membros na tomada de decisões, para garantir a agilidade e articulações exigidas pelo mercado, a modernização administrativa e um líder com perfil de "executivo de empresa".

Por outro lado, Roberto Guimarães (1996) afirma que o cooperativismo oferece diversas possibilidades: inclui setores cada vez mais amplos da população, pode ser uma alternativa de formalização para o chamado setor informal da economia e responde à demanda de uma nova organização econômica, social e política em uma mesma dimensão participativa, além de atuar como elemento de estabilidade profissional e incorporação das mulheres no trabalho (voltaremos ao tema mais adiante).

O fato de o cooperativismo ter sido historicamente (na América Latina, pelo menos) introduzido como ato paternalista e autoritário; de se constituir, em muitos casos, como área de manobra política e de interesses pessoais, mas, ao mesmo tempo, representante de uma real possibilidade de ser um agente de participação e inclusão social ${ }^{3}$, faz dele um objeto de estudo extremamente pertinente para os pesquisadores da dinâmica social, ainda pouco explorada sob esta perspectiva.

Nosso interesse volta-se prioritariamente para o estudo de cooperativas populares por vários fatores: 1) pela grande importância que elas têm assumido no atual contexto socioeconômico e político do país, o que se reflete em seu expressivo crescimento numérico; 2) por terem seus objetivos principais mais afinados com a doutrina fundadora do cooperativismo; 3) porque acreditamos que as contradições e conflitos entre a aplicação da doutrina cooperativista e a atual tendência de incorporação das cooperativas ao modelo da

\footnotetext{
${ }^{3}$ Promovendo a formação de "cidadãos sujeitos da sua história", transformando subjetividades e relações psicossociais e
} constituindo-se como objeto complexo. 
globalização econômica repercutem de maneira incisiva em sua dinâmica funcional e se estendem a seus integrantes num nível pessoal; 4) porque é nelas que poderemos apreender, com mais evidência, os aspectos psicossociais ligados aos seus objetivos facilitadores do exercício da cidadania e empoderamento dos atores sociais.

São a autogestão, a procura da melhoria da qualidade de vida dos cooperativados (bem como da comunidade) e, ainda, a preocupação com os desempregados, os excluídos, os "precarizados" ou os vulneráveis o que constitui o eixo das cooperativas populares - informanos a consultora para formação de cooperativas Sandra Mayrink-Veiga (1997) - em movimento articulado ao desenvolvimento regional sustentado e propositivo na sociedade. A esse respeito, Arruda (1996) salienta que o desafio do cooperativismo popular é conceber a cooperativa como uma comunidade humana que busca o desenvolvimento e o bem-estar sustentável de cada associado e de suas famílias num processo que visa conectar criticamente as dimensões micro (sujeitos ativos e conscientes) e macro (globalização cooperativa) da condição humana.

Para o psicossociólogo Eugène Enriquez: "Não se trata unicamente de querer coletivamente; trata-se de sentir coletivamente, de experimentar a mesma necessidade de transformar um sonho ou uma fantasia em realidade cotidiana e de se munir dos meios adequados para conseguir isso" (Enriquez, 1994, p. 57).

O viés institucional nos parece pertinente ao estudo das cooperativas populares. As instituições, na abordagem psicossocial, são manifestações e concretizações das realidades da vida em sociedade, a partir da qual criam suas leis, suas regras, seus códigos, suas ideologias. Impõem costumes, prêmios e punições, transmitem valores e estabelecem limites. Produzem coisas ou pessoas, mas também protegem, dão garantias; alimentam egos e ilusões e servem como projeção para as fraquezas e anseios da alma humana. São espaços de mediação entre a vida individual e a vida coletiva. É desse lugar que o psicossociólogo, ao fazer uma análise da instituição, vai dirigir seu olhar tanto para o lugar da instituição no sistema social, econômico e político, quanto para o que é da ordem do funcionamento formal, assim como procurará apreender o que é da ordem do sujeito e das relações interpessoais. A relação individual com as instituições se enraíza na identidade social, cultural e política, que se "realiza" na prática cotidiana, mobilizando nos atores sociais investimentos e representações, permitindo-lhes assim se identificarem com o conjunto social. Perceber as dimensões essenciais dos problemas, dos conflitos, dos processos de idealização e de alienação, dos investimentos pessoais, pode ser um caminho para a transformação da ação individual e coletiva, para a vontade de inovar e de buscar um prazer mais legítimo para cada um

A metodologia de pesquisa utilizada se define como pesquisa-participante (Brandão, 1984; Thiollent, 1988), permitindo o conhecimento da realidade das cooperativas e da vivência e das expectativas de seus integrantes através da participação dos membros da equipe de pesquisa nas diferentes atividades que compõem as práticas institucionais.

Além das entrevistas realizadas com profissionais de instituições incubadoras, notas e registros feitos em eventos e reuniões regionais e setoriais de cooperativas, sete cooperativas foram escolhidas como campo de pesquisa: 3 de prestação de serviços (limpeza, serviços hidráulicos e elétricos) e 4 de produção (3 de costura e 1 de artesanato). As incubadoras nos indicaram algumas delas e outras procuramos diretamente por contatos feitos nos eventos dos quais participamos, buscando prioritariamente atender o critério de formação espontânea da cooperativa a partir da iniciativa da própria comunidade. Elas se localizam em bairros da periferia urbana, e uma em uma pequena cidade no Estado do Rio de Janeiro, têm por volta de 2 anos de existência e algumas já não conseguem mais manter o mínimo de 20 cooperativados, mas insistem em serem chamadas de cooperativas.

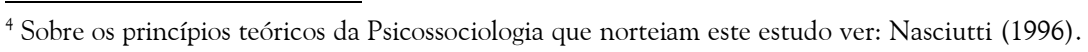


As técnicas de investigação usadas incluíram observação-participante in loco de reuniões, assembléias e atividades cotidianas de cooperativados, registradas em diários de campo; coleta de documentos (textos, folhetos, cartazes, cartilhas) e entrevistas semiestruturadas com cooperativados (22 no total) ocupando diferentes lugares e papéis nas cooperativas eleitas, visando apreender representações subjetivas sobre o cooperativismo, sobre sua cooperativa em particular e as ressignificações psicossociais ligadas ao status social de cooperativado ${ }^{5}$. As entrevistas permitiram ainda obter dados sobre a dinâmica funcional da cooperativa que, confrontados com os dados obtidos pelas outras técnicas de pesquisa, apontaram para o equilíbrio ou para conflitos e contradições institucionais.

Categorias de análise foram criadas a partir da problemática levantada, assim como do discurso dos entrevistados e dos registros da observação-participante. Optamos, nesta apresentação da análise das cooperativas visitadas e das falas de seus sujeitos, por um formato de relato que - resguardado o rigor metodológico que caracteriza a pesquisa científica buscasse dar visibilidade prioritariamente às pessoas e a seus discursos, aos grupos instituídos e a suas inter-relações, ao invés de apresentarmos nossos dados sob a forma de gráficos e estatísticas.

Seguindo nosso objetivo de buscar apreender diferentes aspectos das cooperativas populares urbanas no Rio de Janeiro, dividimos a apresentação em três blocos: o lugar da instituição cooperativa no mundo no qual se insere, a organização cooperativa e as relações que nela se traçam e a cooperativa como é vivida, subjetivamente, por seus integrantes.

\section{A cooperativa popular e o mundo contemporâneo do trabalho}

O papel das incubadoras demonstra-se crucial na formação das cooperativas e, em muitos casos, acaba por se criar um vínculo de dependência das cooperativas com relação às entidades incubadoras. Todas as cooperativas pesquisadas receberam alguma forma de assessoria ou orientação em seu processo inicial de fundação, quer a demanda tenha surgido do próprio grupo fundador ou não. Nossas entrevistas com técnicos de incubadoras e assessorias de apoio à formação de cooperativas e, ainda, as entrevistas realizadas com os próprios cooperativados, além da observação participante das práticas cotidianas das cooperativas, conduziram-nos a algumas constatações e reflexões que consideramos importantes: no discurso dos entrevistados evidencia-se o aspecto técnico-educativo do treinamento recebido; no entanto, não há referências ao caráter doutrinário dessas assessorias no sentido da garantia da transmissão e da incorporação dos princípios cooperativistas, já que muitos dos cooperativados não demonstram conhecer a história do processo de institucionalização por terem ingressado na cooperativa após o período de sua criação e incubação. Parece prevalecer nessas assessorias o cunho de capacitação instrumental-técnico-legal necessário para a formação e sobrevivência de uma cooperativa como empresa competitiva no mercado capitalista vigente, conforme define um cooperativado:

...eles fazem esse trabalho que eles chamam de incubação. Criação da cooperativa, cuidando também da parte legal; fizemos um curso de um ano, uma vez por semana, aprendendo tudo: notas fiscais, como proceder, deu uma idéia geral para todo mundo, entendeu? (R., 34 anos).

\footnotetext{
${ }^{5}$ Além de cooperativados, incluem-se entre nossos entrevistados 2 pessoas que pertenciam a uma cooperativa de serviços e que no momento da pesquisa continuavam a exercer as mesmas atividades, porém, como contratadas por uma empresa.
} 
A questão da educação (presente nos princípios cooperativistas) não parece ser abordada com ênfase nesse processo. Também não parece haver uma preocupação com a importância da mudança cultural, da desnaturalização das relações tradicionais patrãoempregado, tão fundamentais na formação do sujeito cooperativado e pré-requisito para o sucesso da autogestão. Essa constatação parece vir ao encontro das declarações de Roberto Rodrigues (1999b) sobre o novo perfil das cooperativas no mundo capitalista competitivo.

Em termos institucionais, podemos supor uma origem harmoniosa dessas cooperativas - em suas relações históricas e contextuais - com seu meio. Isto é, o processo de institucionalização das cooperativas populares no Rio de Janeiro parece adequar-se aos propósitos do sistema socioeconômico vigente, sem constituir-se necessariamente como ameaça nem se apresentar como modelo alternativo nas relações sociais de trabalho. A esse respeito concordamos com Luiz Razeto (1997) quando, ao defender os movimentos autogestionários e cooperativos como motores da economia solidária, admite que os mesmos têm apresentado limites e situações de crise:

Eles não têm conseguido se impor como sujeitos históricos autônomos, dotados de uma capacidade efetiva de direção de mudanças econômicas e do desenvolvimento... Devemos reconhecer que se mantêm em um plano de subordinação a respeito das grandes tendências da economia e da política (Razeto, 1997, p. 13).

Isso não significa, no entanto, que em muitos casos, as cooperativas não surjam como movimentos sociais instituintes, principalmente aqueles que emergem naturalmente da ação voluntária e empreendedora de grupos e atores sociais. Isso efetivamente acontece ${ }^{6}$. No entanto, há um processo de "ajustamento" ao longo dos treinamentos através do qual as leis do "mercado livre" definem os limites e as possibilidades da ação cooperativa. As contradições entre as lógicas da cooperação (que se pretende regendo internamente a instituição) e da competição (que se espera no mercado externo) não chegam a ser problematizadas no processo de incubação.

Prepara-se um trabalhador para se tornar sócio de uma organização (preparo esse, essencialmente técnico), aspecto fundamental para a criação e para a sobrevivência da instituição. Não se prepara, porém, o indivíduo para romper com a cristalização e com a naturalização de lugares no mercado de trabalho em direção a novas relações psicossociais com o outro, com o coletivo. A assessoria, via de regra, prepara o membro da organização, não a pessoa do trabalhador. Ademais, no contexto socioeconômico vigente, não parece estar havendo nenhum movimento efetivo de mudanças na cultura que define a valorização institucional atribuída às cooperativas. Dados estatísticos evidenciam o que a fala dos cooperativados já denuncia: as cooperativas são vistas, sobretudo as de caráter comunitáriopopular, como coisa menor na "bolsa de valores" das representações sociais. A mesma mercadoria, o mesmo serviço prestado recebem avaliações (financeira e social) diferentes conforme sejam originários de uma indústria ou de uma empresa organizadas nos moldes tradicionais ou quando oferecidos por uma cooperativa.

A maioria das cooperativas populares mantém relações institucionais, principalmente através das diretorias, com outras cooperativas. Essas relações parecem ser:

a) instrumentais, no sentido de se conseguir trabalho:

A gente conhece, mas a gente não se mete no trabalho deles. Mas se a gente precisar de alguma coisa, a gente pode ir até eles que eles podem nos auxiliar, o que a gente tem que fazer, onde ir, outros cedem máquinas para gente (E., 28 anos).

\footnotetext{
${ }^{6}$ As cooperativas de costura, dentre as cooperativas pesquisadas, foram aquelas que surgiram da organização voluntária da comunidade. A partir da iniciativa de uma ou mais costureiras, os grupos foram se organizando e, com o apoio das incubadoras, instituindo-se como cooperativas.
} 
b) educativas, para aprender o processo funcional:

...para saber o que fazem para elas nos passarem e melhorar a tarefa (R., 29 anos).

c) de cooperação ou parceria:

É que dentro da Universidade era esse ato cooperativista, quem tava mais preparado entrava e sobredividia os postos. É porque evita a concorrência entre os cooperativas (S., 25 anos).

Os órgãos estaduais, ou mesmo nacionais, são acusados pelos cooperativados de não representarem nem atenderem aos interesses das cooperativas populares, que têm, por esse motivo, buscado criar associações menores, formadas por 4 ou 5 cooperativas de comunidades próximas que visam se fortalecer na defesa de seus interesses. Essas iniciativas, no entanto, não têm sido bem sucedidas e são vistas por representantes desses órgãos como fator de enfraquecimento institucional. Esse é um aspecto que merece ser mais profundamente estudado. Nos eventos dos quais participamos, não só a questão do lugar marginal que as cooperativas populares ocupam no movimento cooperativista brasileiro, mas o conceito mesmo de "cooperativa popular", eram questionados e discutidos pelos participantes com argumentos fortemente carregados de afeto e emoção, sem que as discussões buscassem o sentido desses "mal ditos" sentimentos de exclusão ou injustiça vividos.

\section{O "nós” e "os nós" na organização e os desafios da cooperação}

A ausência de rotina caracteriza o cotidiano das cooperativas (principalmente as de produção) no discurso dos entrevistados, nos registros dos diários de campo da equipe e nos debates presenciados nos eventos:

...olha, aqui a gente não tem horário fixo, nossos horários a gente é que faz (J.R., 44 anos).

...um dia calmo, o outro de desespero (R., 35 anos).

Já chegou época da gente trabalhar sábado, domingo, feriado, até 11 da noite... essa semana está tudo parado (M.E., 45 anos).

A liberdade na escolha do horário e do ritmo de trabalho é apontada pelos cooperativados como uma das vantagens (e como veremos, motivações) do trabalho em cooperativas, por motivos que vão desde aspectos como a organização do tempo de dedicação à família e outras atividades, até à importância de fazer seu horário sem fiscalização de um terceiro.

Por outro lado, a falta de rotina também pode significar falta de trabalho e conseqüentemente, ameaça à continuidade da própria instituição e à garantia de remuneração. $\mathrm{O}$ discurso dos entrevistados quanto à ocupação do tempo é recheado de menções aos aspectos positivos do ritmo intenso de trabalho, garantia de ganhos pessoais, da sobrevivência da instituição e do sucesso do modelo cooperativista. 
A divisão de tarefas administrativas e diretivas nas cooperativas pesquisadas obedece, na grande maioria dos casos, aos princípios do cooperativismo. Existem sempre as figuras do presidente, dos diretores, do tesoureiro, e esses cargos são ocupados de forma rotativa pelos integrantes das assembléias que elegem a diretoria:

... a gente tem o presidente, tem a administrativa e tem a financeira, só que elas não fazem só aquele serviço específico, faz tudo. E abre espaço para os cooperativados, em eleição... de três em três meses... quando a gente tinha posto de trabalho a gente trocava de coordenação geral para poder cada cooperativado saber a responsabilidade que tem uma diretoria e conhecer $\mathrm{da}$ cooperativa como é (S., 25 anos).

Os princípios autogestionários se fazem ver no gerenciamento das cooperativas, principalmente nas de produção:

Aqui tem presidente, diretor administrativo e o tesoureiro. Aí depois nós fizemos um conselho fiscal, aí elegemos 3 pessoas para o conselho fiscal. E o resto... se eu tô aqui o que tem para resolver, eu resolvo; quem tiver aqui resolve, porque aqui todo mundo sabe tudo (M.U., 52 anos).

Todas as pessoas entrevistadas declararam que as decisões são tomadas em assembléias, confirmando a aplicação da doutrina cooperativista nas práticas institucionais das cooperativas:

Tudo em assembléia... as decisões a tomar, a gente se reúne aqui e passa uma para outra, cada uma dá sua opinião; a maioria, o voto majoritário é que ganha (S., 25 anos).

Não deixa de haver uma centralização de poder decisório nas mãos do presidente e da diretoria, que são legitimados pelos próprios cooperativados para tomarem decisões emergenciais em nome do coletivo:

... só que algumas coisas a diretoria vai decidir por conta própria, porque nem tudo dá para ser decidido em reunião, algumas compras, decisões de trabalho, a gente tem que decidir por conta própria, porque nem tudo dá para ser decidido em reunião, algumas compras, decisões de trabalho, a gente tem que decidir rápido (R., 34 anos).

Essas mudanças em direção às diretrizes do mercado foram previstas por Roberto Rodrigues (1999b) como destacamos antes, sobretudo a não participação dos membros nas tomadas de decisões visando a agilidade e a competitividade.

Existem ainda as críticas aos que não manifestam a adoção da filosofia cooperativista quanto à importância da participação coletiva para a existência da cooperativa:

Olha, tem gente que só vem aqui como se fosse uma firma, querer trabalhar e receber dinheiro no final do mês. Não liga para o que está acontecendo... não quer nenhuma responsabilidade. Então, prejudica um pouco o processo... Só que tem uns que incorporam a camisa e tem outros que só ficam no trabalho... e a responsabilidade é da diretoria (S., 25 anos).

Muitas vezes, o conselho de ética é chamado para julgar comportamentos inconsistentes com a proposta instituída:

O conselho de ética é para por o cooperativado no lugar... passar dos limites, brigas no setor...

aí tem o conselho de ética para punir, né (A., 31 anos). 
Esses dispositivos disciplinadores parecem resquícios das relações trabalhistas tradicionais, permitindo, no entanto, que as regulações dos papéis e das normas mantenham a estabilidade das relações interpessoais, o que será discutido adiante.

Finalmente, a interiorização dos princípios cooperativistas nas formas como se dão as relações de poder são aqui exemplificadas:

Você sabe que a relação interpessoal é muito difícil... A gente tem que saber que não existe liderança autocrática... Eu sempre questiono isso na questão da cooperativa porque você vê que tem pessoas que montam com vários grupos uma cooperativa e quer ficar a vida toda no poder. Não é assim (E., 28 anos).

Às vezes, a pessoa não está preparada para comandar... (R., 34 anos).

A resolução de conflitos parece seguir o mesmo modelo do processo decisório: a interlocução, o diálogo, as reuniões:

Hoje em dia a gente já olha assim na cara mesmo, fala o que tem que falar... nada assim de magoar o outro, como era... a gente sabe agora falar com o outro, a respeitar o que o outro vai dizer, né (J.F.L., 43 anos).

As dificuldades nas relações interpessoais das cooperativas que visam a autogestão são percebidas e manifestas:

Nosso problemas mesmo é de convívio em grupo, um não aceitar a opinião do outro. Em reunião não, a gente conversa e sempre chega a um consenso, mas assim trabalhar e aprender a receber ordem... eu digo sim, não é receber ordem, mas aceitar o comando de uma pessoa (R., 34 anos).

"Amizade" e "conhecimento" são as palavras mais freqüentes no discurso dos cooperativados para se referirem às relações interpessoais na cooperativa. $O$ fato de pertencerem a uma mesma comunidade e manterem relações de vizinhança, além das relações de trabalho na cooperativa, parece funcionar como facilitador das relações entre cooperativados. A consciência de que parte do sucesso do trabalho cooperativado se deve às relações entre seus membros aparece em frases como:

Aqui sempre foi todo mundo unido, porque se não tiver união não vai render o serviço, vai atrasar (L., 18 anos).

Mesmo nas cooperativas de serviço, onde as práticas diárias são rotineiras e o local de trabalho não é o espaço da própria cooperativa, percebe-se o vínculo entre os cooperativados.

Vemos assim que, se nas relações com o mundo externo as cooperativas populares ainda lutam pelo reconhecimento social, na organização interna, seus atores conseguem se aproximar da doutrina de cooperação e da autogestão.

Mas, porque então, tem gente que deixa as cooperativas? Perguntamos aos nossos entrevistados a que fatores atribuíam a saída de cooperativados que já passaram por suas cooperativas. As respostas podem ser agrupadas em 3 categorias, além de aspectos circunstanciais, como mudança de cidade, casamento, nascimento de filhos ou problemas de saúde:

a) dificuldades pessoais de se ajustarem às propostas ou à filosofia do cooperativismo: 
Eles não conseguiram aceitar esse nosso projeto democrático onde... o que vale é a opinião do grupo (R., 35 anos).

Porque não tem nenhum objetivo na vida, entendeu? São pessoas que preferem trabalhar sempre como empregados, não como trabalhador (E., 28 anos).

b) trabalho e remuneração insuficientes para viver (inconstância de trabalho e dinheiro):

Alguns perderam os postos de trabalho (M.J., 25 anos).

...então elas não podem viver com um dinheiro pouco (V.L., 56 anos).

...as pessoas querem coisas mais práticas, mais viáveis ... ganhar seu dinheiro, pagar suas contas... (R., 34 anos).

c) opção de carteira assinada:

Porque devem ter encontrado um serviço de carteira assinada (L., 18 anos).

$\mathrm{Na}$ verdade, ao falarem dos que saíram, essas pessoas expressaram as maiores idiossincrasias que vivem como cooperativados e que atravessam seus discursos: a dificuldade de se viver plenamente, na realidade cotidiana, a escolha por um modelo de trabalho que se mostra como "experimental", provisório, instável, conflituoso, mas desejável e possível.

Ao serem solicitados a apontarem as vantagens e as desvantagens do trabalho cooperativado, em comparação com o trabalho como empregado de empresas, os entrevistados apontam para uma dinâmica funcional mais flexível nas cooperativas do que nas empresas do mercado formal, como já vimos. As vantagens de se trabalhar em cooperativas aparecem na comparação com o trabalho em empresas, como na liberdade de negociação e no modelo da estrutura funcional autogestionária:

Aqui a gente fala (M., 25 anos).

Em setores diferentes em elo de produção, eu era proibida de estar freqüentando outros setores (R., 35 anos).

Aqui a gente trabalha à vontade, não tem aquela penca de gente no teu pé (R., 44 anos).

Tem seus compromissos, tem as prioridades... mas a diferença é que... a gente vê o serviço mais difícil, a gente conversa e resolve... para ver como é que fica (E., 28 anos).

Você é dona do seu tempo (E., 28 anos).

A aprendizagem também aparece como fator positivo na comparação com o trabalho em empresa:

...e foi aqui que eu aprendi a costurar (R., 35 anos). 
...você se envolve diretamente com seu trabalho, então, você se interessa em saber a mais (R., 34 anos).

Aqui dá oportunidade de aprender qualquer coisa, depende da pessoa (R., 29 anos).

Mas aqui que eu aprendi, de pouquinho em pouquinho... e hoje eu sei fazer até mais. Ia olhando e elas iam ensinando também (J.F.J., 43 anos).

O tipo de investimento pessoal na instituição e no coletivo é marcado pelos vínculos de solidariedade, em comparação com a postura individualista do empregado na empresa:

...pela cooperativa, as pessoas que entravam com seriedade queriam fazer de tudo pra deixar brilhando, fazer o melhor serviço. Já pela firma, o pessoal não trabalha com satisfação, porque a pessoa fica sendo obrigada, vigiada, pressionada (L., 33 anos).

... [na empresa] você vai obrigado e aqui não, é um ajudando o outro. São mais unidos... [na cooperativa] você tem que ter responsabilidade, você tem que ver seu serviço. Ah, acho que posso melhorar... colega, me ajuda? E aí acha a melhor maneira. Numa fábrica você não pode fazer isso entendeu? (R., 44 anos).

A diferença é que tem o companheirismo, você trabalha com todo mundo junto (M.U., 52 anos).

O sentimento de apropriação do trabalho, principalmente nas cooperativas de produção é marcante:

Você, cooperativado, você é produtor de sua coisa, você tem o seu trabalho e esse seu trabalho é uma coisa tua (S.A., 41 anos).

Aqui a gente às vezes trabalha até mais, mas é uma coisa que a gente tá fazendo pra gente mesmo (M.E., 45 anos).

Mas as diferenças entre participar do modelo cooperativista e do modelo empresarial também revelam aspectos negativos do primeiro, segundo nossos entrevistados. As principais desvantagens apontadas referem-se às ausências de garantias e benefícios trabalhistas:

A diferença é que aqui não tem carteira assinada, não tem férias, não tem décimo terceiro salário (S., 25 anos).

Eu preferiria trabalhar de carteira assinada porque... eu tenho meu dinheiro, meu salário no final do mês, certo... é mais por isso, pelo salário (V.L.O., 56 anos).

Lá nós temos nosso salário garantido né, aqui não, então a gente não pode fazer nunca um compromisso contando com o dinheiro daqui... não sabe quanto é que... vai ganhar... é difícil (E.S.F., 46 anos).

Numa fábrica é bom por causa disso. Tendo serviço ou não você vai receber aquilo no final do mês, aqui você só vai receber se tiver serviço (R., 29 anos). 
Os cooperativados demonstram maciçamente que os aspectos positivos superam os negativos quando solicitados a comparar a cooperativa e as empresas nas quais trabalharam. A liberdade na administração do tempo, na escolha das tarefas e do ritmo de trabalho é um dos principais aspectos salientados. Essa liberdade se conjuga à apropriação da força de trabalho e do produto, contrapondo-se, para os cooperativados, à posição de submissão e de obediência características das relações de trabalho nas empresas. É importante a ressalva de que se trata aqui de uma classe social na qual a inserção no mercado de trabalho dá-se, via de regra, pela ocupação de cargos e postos de trabalho sem poder de mando.

Esses fatores, sem dúvida, geram como contrapartida maior investimento das pessoas na instituição, maior sentimento de pertença e conseqüentemente laços de solidariedade mais fortes quando comparados ao trabalho seriado, segmentado e individualizado característico da vida empresarial.

Por outro lado, a falta de segurança, a ausência de vínculos e garantias trabalhistas, décimo terceiro salário, férias e de renda mensal fixa são os grandes entraves do cooperativismo na visão dos cooperativados. Num mundo capitalista, no mundo das "prestações de serviço", dos juros, dos compromissos financeiros mensais, a incerteza dos rendimentos é vivida de forma negativa por essas pessoas. Em nossa sociedade, a "carteira assinada" identifica socialmente o indivíduo e lhe confere status de cidadão. Além, portanto, de se sentirem em desvantagem social frente aos demais trabalhadores pelo fato de as cooperativas serem tratadas como "coisa menor", ainda convivem com a ausência dessa forma de identidade que lhes garantiria inserção social. Isso se aplica principalmente aos homens, inseguros quanto à manutenção financeira da família.

No entanto, ainda assim, o orgulho pela aprendizagem, o investimento pessoal, o sentimento de apropriação da força de trabalho presentes no cooperativismo parecem vir preencher o vazio deixado pelo modelo empresarial das relações de trabalho nessa camada da sociedade, que é assim entendida por Luiz Razeto: "O trabalhador desconhece os processos tecnológicos nos quais participa, limitando-se à execução de atividades sem compreender as relações e o significado delas no conjunto do processo" (Razeto, 1997, p. 15) e que poderíamos também definir como alienação.

Não há perspectivas de trabalho futuro com vínculo empregatício para a maioria de nossos cooperados, que afirmam não se adaptar mais à condição de empregados:

eu não ia mais me adaptar a essa qualidade de vida (R., 35 anos).

não vejo mais possibilidade não. Não me vejo como empregada não (R., 44 anos).

...eu penso assim que ser empregada é difícil, viu, porque você nunca tem o valor que acha que pode ter, é difícil... (R., 44 anos).

Uma delas pretende trabalhar "por conta própria" no futuro...

Minha vontade é essa de ter o meu próprio negócio, de trabalhar pra mim e não trabalhar para os outros (A., 31 anos).

...mas duas gostariam de retomar o trabalho em empresas pela garantia salarial:

...se eu for pensar nisso, eu preferia trabalhar de carteira assinada. Por quê? Porque... eu tenho meu dinheiro, meu salário no final do mês certo... é mais por isso, pelo salário... (V.L.O., 56 anos). 
...ali, depende de quanto eu vou ganhar se vale a pena. É bom você ter uma segurança no final do ano (R., 29 anos).

\section{O “eu” na instituição cooperativa}

A prevalência do desemprego se apresenta como a maior justificativa da opção pelo trabalho cooperativado no relato de metade dos entrevistados. A atração pela filosofia cooperativista teria sido o motivo de escolha de aproximadamente um terço dos entrevistados:

Foi a proposta de método diferente de trabalho. Eu trabalhei 15 anos em fábricas, naquela de pressão e aqui não, a gente tem mais liberdade para trabalhar... também queria ser independente, sem patrão (R., 35 anos).

Para muitos, foram os laços de amizade e solidariedade que motivaram a escolha pelo trabalho em cooperativas:

...o que levou a gente a nos juntar foi a amizade que nós tínhamos e o trabalho que eu gostei demais... (V., 45 anos).

A comodidade e a proximidade dos filhos são fatores que pesam na escolha do trabalho cooperativado, na comunidade, principalmente para as mulheres:

...tá mais perto, é mais cômodo... aqui não tem horário estabelecido nem pra pegar, nem pra largar. Essa foi à vantagem, eu fiquei mais perto da minha filha (E., 28 anos).

Pertinho de casa, não pego condução, posso levar meu filho para o colégio, adiantar o serviço de casa... (M.E., 45 anos).

Esses indicadores corroboram alguns pontos já levantados de que o trabalho nas cooperativas é uma alternativa como qualquer outra no mercado de trabalho, mais do que uma escolha consciente e de exercício da cidadania ou de uma busca de mudança na relação de trabalho. O desemprego é também a motivação maior para o ingresso nas cooperativas nos dados obtidos por Cordeiro (2001) em pesquisa realizada com cooperativas de grande porte do Rio de Janeiro. Mas a autora acrescenta que "depois de vivenciarem a experiência do cooperativismo, acham que a cooperativa tem uma função social e econômica mais abrangente" (Cordeiro, 2001, p. 67).

Essa função aparece em segundo lugar na fala dos cooperativados, evidenciando a importância atribuída a essa filosofia pelas pessoas que optam por ingressar e permanecer atuando nas cooperativas. Em geral, foram esses mesmos entrevistados que apontaram os laços de amizade e a solidariedade comunitária como outro mobilizador de suas escolhas.

Quanto ao significado do trabalho, percebe-se uma diferença nas respostas dos entrevistados em função do gênero e do tipo de trabalho. Mulheres valorizam mais o trabalho da cooperativa pela auto-estima que dele advém. Da mesma forma, pessoas que trabalham em cooperativa de produção valorizam mais a atividade de trabalho. Uma hipótese para esse fato poderia ser o "empoderamento" dessas pessoas através da apropriação de sua força de trabalho e do orgulho do produto gerado. 
Para nossos entrevistados, o trabalho significa:

a) aumento da auto-estima e satisfação pessoal:

Para mim é auto-estima... é uma satisfação (R., 35 anos).
É fazer um trabalho assim bem-feito, que o pessoal elogie, né?! (M.J., 25 anos).

Foi muito bom pra mim, pro meu ego ,né?! Porque eu mesmo reconheci que eu sou capaz... achava que era inútil (R., 44 anos).

b) mudança (independência) no lugar na família pela contribuição financeira no sustento da casa:

A gente tem o nosso dinheiro e se tiver que comprar alguma coisa a gente vai e compra, se tiver que agradar os filhos vai e agrada, entendeu? E não tem que ficar dando satisfação e... pra gente mostrar que é alguém (S., 25 anos).e

...é ganhar o sustento da gente. Porque não trabalhar fora que a gente ganha dinheiro para ajudar no sustento da casa? (L., 33 anos).

Há uma valorização [do marido, dos filhos...] Minha filha... tem um espelho pro trabalho e eu acho isso importante. As mulheres se sentem mais valorizadas (E., 37 anos).

c) oportunidade de aprendizagem e de criação de vínculos sociais:

Aqui na costura eu aprendi a costurar (R., 19 anos).

Trabalhar pra mim é tudo... Parece que minha mente tava fechada, então, comecei a trabalhar e aprendi muita coisa, fiz muita amizade (A., 31 anos).

Pra gente que é mulher, trabalhar é bom. Você conhece pessoas novas (S., 25 anos).

Eu gosto muito de aprender coisas novas, aqui ... é um aprendizado, cada dia você aprende mais... (R., 44 anos).

O desafio cultural que representa o exercício da autogestão na organização social brasileira (calcada em relações de poder verticais, autocráticas, centralizadas e historicamente cristalizadas) é grande, pois, como os sujeitos-atores-sociais trazem esse modelo tradicional dentro de si, podem reagir às iniciativas que avançam em direção à horizontalidade e à circularidade dessas relações com medo, desconfiança e insegurança e tendem a retornar ao seio acolhedor do injusto, mas conhecido patronato:

Você sabe que a relação interpessoal é muito difícil... A gente tem que saber que não existe liderança. Eu sempre questiono isso na questão da cooperativa porque você vê que tem pessoas que montam com vários grupos uma cooperativa e quer ficar a vida toda no poder. Não é assim (E., 28 anos, já citado).

Nosso problema mesmo é de convívio em grupo, um aceitar a opinião do outro. Em reunião não, a gente conversa e sempre chega em um consenso, mas assim, trabalhar e aprender a 
receber ordem; mas eu digo assim, não é receber ordem, mas aceitar o comando de uma outra pessoa e às vezes essa mesma pessoa não está preparada para comandar. O problema é de comunicação, mas também de aceitação (R., 34 anos).

Percebe-se nessas falas as idiossincrasias de modelos conflitantes: por um lado, as dificuldades do exercício cotidiano das relações interpessoais horizontais, por outro, a busca de seu fortalecimento, aumentando a autonomia do grupo.

Salientamos no início deste trabalho o quanto os vínculos que unem as associações e empreendimentos locais a uma comunidade podem servir como alavancadores do desenvolvimento local e da organização social dos sujeitos sociais. Um dos aspectos que observamos e buscamos apreender na pesquisa de campo com as cooperativas foi a sua inserção na comunidade local, sua representatividade, as relações interinstitucionais de troca, dependência e influência. Esse lugar da cooperativa popular em sua comunidade é importante porque pode funcionar como modelo, como referência, como fator de mobilização social, mas também pode funcionar como espaço de manipulação, de centralização de poder, de cooptação, principalmente quando exercido, perversamente, em nome do associativismo.

\section{Co-operação e autonomia: conjugação possível}

A complexidade psicossocial do universo institucional cooperativista se fez ver neste estudo. As contradições e desafios próprios a um modelo cujos princípios não condizem com a filosofia predominante na sociedade moderna, capitalista e individualista, se revelam nas formas como essas organizações se inserem em seus contextos locais e tentam buscar espaço no mercado competitivo de trabalho, que só lhes reserva o lugar desvalorizado das sobras ou da acomodada adequação. As dificuldades interpessoais das relações de poder, da tomada de decisões, das práticas de subjugação cristalizadas historicamente persistem nos movimentos autogestionários emergentes num nível micropolítico. Mas é nesses mesmos sujeitos que criam e dão forma a esses modelos associativos populares que o ideal cooperativista se revela de modo mais evidente. Os prazeres da apropriação da força de trabalho, da disposição do tempo, da possibilidade da aprendizagem, da auto-estima recuperada ou descoberta mesclamse à satisfação da descoberta do outro como possível co-operador e não apenas como competidor.

Desde o início e durante todo o período que durou este projeto, a equipe buscou encontrar nas falas, nos fazeres, nas práticas cotidianas das cooperativas populares, dados que permitissem estabelecer inter-relações entre a atividade cooperativista e o exercício da cidadania, a autonomia solidária, a existência de sujeitos que mantém com o trabalho uma relação de propriedade e não de servidão, ou seja, evidências da força (e da valorização) da ação coletiva. Quando detectávamos na voz ou na ação de um de nossos entrevistados alguma atitude percebida como individualista ou centralizadora, tendíamos a acreditar ser isto um analisador da dificuldade ou da impossibilidade da cooperação, da ação coletiva. Uma de nós trouxe para a reflexão da equipe um texto de Bader Sawaia (1994), provocando o questionamento sobre o juízo de valor que poderíamos estar aplicando em nosso olhar para o cooperativismo. Será que muitas vezes podemos estar priorizando, ou melhor, definindo o modelo coletivista como um ideal que não permite a manifestação de expressões de busca de satisfação individual, incompatibilizando-as com a cooperação? Será que quando nos deparamos com reclamações de que, quando se junta todo mundo para dividir as sobras e cada cooperado só recebe 10 reais, isso significa falta de consciência cooperativista? Será que pensar o cooperativismo não deve ultrapassar a visão do coletivo, mas atentar também para o 
sujeito e suas necessidades e desejos? O fato de termos uma identidade de sujeito com aspirações particulares não deve ser encarado como desviante do modelo cooperativista. Talvez esse seja o grande problema encontrado no núcleo interno das cooperativas, em seu cotidiano, o conflito entre ser sujeito ou ser coletivo. Por que não pensar que se pode ser sujeito e coletivo?

Essas múltiplas faces da instituição cooperativa não devem ser negligenciadas. Estamos acostumados a pensar sob a perspectiva capitalista de produção, que nos reporta a um modelo dualista de apreensão da realidade, onde só há lugar para o nível econômicoindividualista ou para o nível social-coletivista. Não podemos nos esquecer, no entanto, que a cooperativa é um espaço privilegiado para a quebra desses paradigmas e a fomentação de uma nova realidade, na qual haja espaço para esses dois níveis de atuação. Construir isso será, sim, a forma de fazer do cooperativismo uma terceira via no modo de produção socioeconômico e um modelo de relação de trabalho onde indivíduos heterônomos se tornem sujeitos autônomos e atores coletivos.

Cooperation and autonomy: the facing cooperative societies

A possible alternative to the exclusion from the formal work market, cooperative working in the working classes, rapidly stops at the social hierarchies (empployer-empployee relationships), but it insists on the disposition of citizenship and in the emerging solidarity through a culture that is installed. The legitimacy of a new psycho-social place is made present in the talk of members of cooperatives, in accordance with research data, in an institutional coverage, carried out in popular urban cooperatives in the city of Rio de Janeiro. The results, from interviews and observations made, point to the perception of the efficiency of collective actions, of the fruits of solidarity and of cooperation in the generation of earnings, and of the possibility of other forms of working links that do not pass necessarily through relations instituted by dependency. The change in self image, the consciousness of unknown potentialities, reposition the worker vis a vis his social group. On the other hand, being formally employed, a title of citizenship in our social organization, highlights the one element that, because of its absence in the cooperative universe, interferes with the investment that the workers make in the cooperative institution beyond the governmental bureaucratic obstacles.

Keywords: Co-operation, community, social subject.

Endereço para contato com as autoras: caryara@hotmail.com

Manuscrito recebido em: 01/07/2003

Pareceres enviados às autoras em: 28/08/2003

Aprovado para publicação em: 07/09/2003

\section{Referências Bibliográficas}

Arruda, M. (1996). Globalização e sociedade civil: repensando o cooperativismo no contexto da cidadania ativa. Rio de Janeiro: Instituto de Políticas Alternativas para o Cone Sul.

Brandão, C. R. (Org.). (1984). Repensando a pesquisa participante. São Paulo: Brasiliense. 
Cordeiro, S. M. (2001). O Papel das Cooperativas de Trabalho no contexto das Transformações da Sociedade Brasileira: Um estudo de caso no município do Rio de Janeiro. Dissertação de Mestrado, EBAPE, Fundação Getulio Vargas, Rio de Janeiro.

Enriquez, E. (1994). O vínculo grupal. In A. Lévy, A. Nicolaï, E. Enriquez \& J. Dubost (Orgs.), Psicossociologia: análise social e intervenção. Rio de Janeiro: Vozes.

Guimarães, R. (1996). Cooperativismo y participación popular en América Latina y el Caribe (reflexiones en busca de un enfoque para la Cepal). In A. C. Viadel (Org.), Sociedad solidaria y desarrollo alternativo. Espanha: Fundo de Cultura Económica.

Martins, T. C. D. (1999). Projeto Rio Cooperativa/Sebrae (nota técnica para seminário). Rio de Janeiro: Sebrae.

Mayrink-Veiga, S. (1997). Entrevista com Sandra Mayrink Veiga. Proposta, 75, 59-66.

Nasciutti, J. C. R. (1996). A instituição como via de acesso à comunidade. In R. H. F. Campos (Org.), Psicologia social comunitária. Petrópolis: Vozes.

Nasciutti, J. C. R. (2000). Participação comunitária para uma melhor qualidade de vida, Documenta EICOS, 8 (11). Programa EICOS, Instituto de Psicologia, UFRJ, Rio de Janeiro.

Pajoni, R. (1996). La question urbaine. In Centre de Recherche et d'Information pour le Développement (Org.), Un monde solidaire: comprendre pour agir (pp. 179-197). Paris: Syros.

Razeto, L. M. (1997). O papel central do trabalho e a economia de solidariedade. Proposta, 75, 91-99.

Rodrigues, R. (1999a, 11 de abril) O novo cooperativismo (entrevista com Adriana Lorete). Jornal do Brasil, pp. 1- 2.

Rodrigues, R. (1999b). Os caminhos do cooperativismo na geração de trabalho e renda. Palestra proferida em abril no Sebrae, Rio de Janeiro.

Sawaia, B. B. (1994) Cidadania, diversidade e comunidade: uma reflexão psicossocial. In M. J. P. Spink (Org.), A cidadania em construção: uma reflexão transdisciplinar. São Paulo: Cortez.

Thiollent, M. (1988). Metodologia da Pesquisa-Ação. São Paulo: Cortez. 